\title{
The Call for Higher Education to Develop Diversity Competencies with the Goal of Preparing Business Students for the Global Marketplace
}

\author{
Roxanne Helm-Stevens \\ School of Business and Management, Azusa Pacific University \\ 901 East Alosta Avenue, Azusa, CA, 91773 USA \\ Tel: 1-626-815-6000Ｅ-mail: rhelm@apu.edu
}

Linda Hunt

School of Business and Management, Azusa Pacific University

901 East Alosta Avenue, Azusa, CA, 91773 USA

Tel: 1-626-815-6000Ｅ-mail: lhunt@apu.edu

\begin{abstract}
Institutions of higher education must respond to the urgent need that exists for organizations operating in the global marketplace to hire and retain professionals prepared to think critically about multifaceted diversity issues in the workplace. Where do organizations find managers and supervisors equipped to handle the multifaceted issues of diversity facing global firms?

Unfortunately, it seems that they cannot rely on business schools. How can business schools assist future executives and managers to develop diversity competencies necessary to compete in the global marketplace? This paper will explore diversity from an organizational and educational context, looking at the concept of diversity and exploring the value of teaching a diversity curriculum.
\end{abstract}

Keywords: Diversity competencies, organic diversity, global marketplace, global organizations 


\section{Introduction}

According to James Lynch, the problem with the absence of multicultural education and the lack of curriculum is a lack of synergy (1989). Higher education is recognizing the need to prepare students for the diverse world ahead of them. Kathryn Campbell suggests the diversity educational initiative has moved from advancing social justice to realizing it must promote academic excellence and engagement (2007). The inference is that diversity education is in transition and that it is time to stretch beyond the boundaries (Campbell, 2007). It is apparent that we need to reach the next generation and prepare that generation for the global market.

\section{Understanding Cultural Diversity}

Trying not to define normal but to understand others is the first step in beginning to open up the dialog for diversity. Defining the term culturally diverse refers to the qualities that make a person unique. Author Ricardo Garcia (1998), states that frequently diversity is thought of as something that deviates from the norm. If we define ourselves and a particular culture as normal, than the danger is that every other culture, by inference, is not normal. According to Garcia (1998), we need to come to terms with the concept that being unique or different isn't being abnormal. Education is the next step in valuing diversity.

Diversity is being able to appreciate the differences in cultures, humanity and having respect for experiences that are unlike the ones we know, according to Iowa State University's college of liberal arts and science, (2009). If we are to comprehend diversity and the differences of culture, we need to begin with an exploration of that understanding with a focus on the global marketplace.

Appreciating differences and recognizing these differences in providing education is critical and will help in assuring that all of us can function in a global world. It would be arrogant to think that only one way or one culture is right, yet some educational perspectives have supported that view. Paul L. Locatelli (2002, p.1), states, "We have to understand how our lives are vitally linked to Earth and all who live on it." The implication is that we have a global responsibility to comprehending the differences that make us unique on this planet.

\section{The Concept of Multicultural Education}

The concept of multicultural education has been around since the sixties. In his book Education in a Multicultural Society, Fred Rodriguez (1983, p.3) states, "multicultural education recognizes cultural diversity as a fact of life in American society, and it affirms that this cultural diversity is a valuable resource that should be preserved and extended." What is significant about Rodriguez's statement is that cultural diversity is viewed as a precious resource. Higher education must also recognize this is a precious resource and curriculums 
should reflect a stronger commitment to diversity. The benefit of multicultural education is developing and preserving that resource to be used to the greater good of all of us.

It is critical that higher education offers diversity curriculums that prepare today's students for the global market place. Being able to compete in the world's more complex markets and know how people from different cultures think and solve problems is an essential skill. According to Dodson, the workforce today is much more complex than in prior decades (2002). Global companies are looking for talented thinkers that can help them retain their competitive edge on the world stage. If you are not competitive and current with respect to in the trends of the marketplace and the people that operate in that marketplace, you risk becoming obsolete. Capps warns that a lack of diversity knowledge could swiftly leave your company falling behind and limit the company's usefulness (2002). Higher education must be committed to turning out students that are well equipped with a business worldview of diversity issues.

\section{Multicultural Educational Issues}

Preparing students at the university level to be able to compete in the global workforce is essential. Being well versed in the understanding of diversity issues is imperative. Education should provide a competitive edge for the student to be able to compete in the global marketplace. The need for multicultural education is more relevant that ever. According to Haskins and Kirk-Sanchez (2006), ethnic minority populations have increased tremendously over the last ten years. Latino and Asian groups make up the highest concentrations of the changing demographics (Haskins \& Kirk-Sanchez, 2006). According to Barbara Bowman (1994), educational performance differences appear early in children from diverse backgrounds.

Global economies dictate how we need to respond to the demographic changes that indicate an increasing populous of Hispanic, African American, and immigrants into our educational system and society (Ward, 1992). If we fail to respond from an appropriate educational standpoint, there will be a financial implication and well as a societal implication. According to Rodriguez (1983), the multicultural movement has not been well defined or understood. If the multicultural movement is not understood, the lack of synergy in diversity education will continue. Author Christine Clark (2003), believes that multicultural organizational development is an essential component in making multicultural education work.

Lynch (2009), suggests that multicultural education is a right and a responsibility. It is simply a necessity in preparing students for today's global marketplace. "Mastering global diversity means understanding the differences that exist within countries as well as between them" according to Gundling and Zanchettin. (2006, p. 1). Reaching an understanding of the multicultural movement is paramount. The goal pursued in achieving multicultural diversity is acceptance, respect and understanding of what makes us unique, and to value 
those differences. According to Guang-Lea Lee (2002), one challenge is in creating an educational environment that promotes respect for diversity.

While the subject of educating students about diversity in a global environment sounds like a worthy cause, it is also perceived by some as our duty to do so. Author Rosa Hernandez Sheets (2003), states that multicultural education is a responsibility to our children. According to Garcia (1998), we have a responsibility to the global cause to recognize that education must cross cultural barriers.

Most educators agree that they would like to reach the goal of having a diverse multicultural curriculum that would bring students together. Some commentators contend that the problem of not achieving equal education and the lack of effective diversity education is because of the teachers themselves. According to Jost, Whitfield and Jost (2005), teachers often do not have the background, knowledge or historical understandings of the various cultures to fix the inequities.

Education has a key role and a responsibility in creating a multicultural society. According to Garcia (1998), cultural self-identity development is formed in the educational environment. This is the reason why a program that embraces and teaches cultural diversity in an effective way is so important. Garcia (1998) believes that there is a problem of elitism that affects curriculum in schools. Elitism is not intentional, but a by-product of the way teachers were trained, as well as a consequence of their own biases. Being able to openly address the problem and work together to improve it is what is important going forward. Embracing diversity needs to start with education.

Doing business in the global marketplace requires a broad understanding of diversity issues. Higher education is barely responding to that need. It is important from a global perspective to understand why diversity education is needed. According to Trompenaars and Turner, each culture solves problems differently (1997). To be successful in the global marketplace it would be advantageous to know how different cultures solve problems and dilemmas. "Culture patterns determine the whole field of business relationships (Trompenaars \& Turner, 1997, p.16).

We must understand how different cultures react and think to tackle the world marketplace. More importantly we must educate business students in higher learning to understand the differences between various cultures. University curriculums must offer an in depth study of diversity from a global and business perspective.

\subsection{An academic perspective of diversity coursework}

In their book, Teaching Diversity: Listening to the Soul, Speaking From the Heart, Joan Gallos and V. Jean Ramsey (1997), introduce us to 15 colleagues who write about their experiences in teaching diversity courses. Narratives describe how their own identities and 
experiences shaped their views of the world and their roles as diversity educators. The authors assert that "Diversity education must begin with the individual but cannot remain there; it must explore the power of institutional, structural and systemic forces to affect lives" (p. 214). Because of the power of institutional, structural, and systemic forces, they further state that we need to learn to look at the world through others' perspectives to work together. This supports Thomas and Ely's (1996) approach to viewing successful diversity efforts as ones in which the organization is constantly learning and relearning from its own members.

Pierce (1993) suggests that cultural diversity in the United States presents important challenges with regard to social justice, equity, and economic development, thus making education in diversity a critical responsibility of colleges and universities. Indeed, because university life is frequently multicultural in itself, it provides a rich opportunity for students to learn about diversity first hand (Adams \& Zhou-McGovern, 1990, 1993). However, the question remains as to whether content and delivery of diversity courses contribute to creating organizations that are effective in maximizing contributions for strategic advantage.

Recent discussion of diversity suggests there is a connection between the business and academic perspectives about diversity training and education; and the literature shows that methods vary greatly in how education and training are delivered to employees. Most literature from the business perspective continues to emphasize the importance of such things as awareness of individual differences, working effectively together, managing conflict, and communication. On the other hand, the literature cited from the academic perspective often stresses cultural understanding and change.

According to Day and Glick (2000), the two perspectives of diversity training and education - business and academic - may differ. They compared the results of two investigations: the first, a content analysis of diversity course syllabi; the second, a survey of the diversity management skills HR managers report are needed in college graduates. The gaps identified in this study demonstrate the need to evaluate the link between diversity course content and organizational needs and perhaps to allow students the opportunity to practice skills that are relevant to career success. Although it is up to faculty and the academy in general to clarify the objectives of diversity coursework, it is important to realize that currently there may be a gap between the skills taught and those desired by HR managers.

\subsection{Diversity education in business schools}

How do executives and managers develop diversity competencies if their company is not providing opportunities beyond training aimed at eliminating bias or eliminating reliance on stereotypes? Unfortunately, they cannot rely on business schools either. Not surprisingly, business school curricula are filled with classes on finance, management, accounting, and leadership. Some of those schools also contain concentrations on so-called soft skills, such as human resources and communications. 
Of the 28 universities in California accredited by the Association to Advance Collegiate Schools of Business that offer undergraduate degrees in business and/or management, none include diversity as a concentration or area of specialty, while only nine include a course in diversity and none offer more than one course.

If California is any indication, diversity is not a skill that is being widely taught in business schools. If any state would be home to business schools with a strong emphasis on teaching diversity skills, it should be California since it is the most diverse state in the United States.

This omission is not explained by the fact that diversity is a soft skill; communication is a soft skill, and at least 20 of those same business schools offer a course in communication. Nor is this explained by the fact that diversity is people-oriented; almost all of those schools offer at least once course in human resources management and nearly half offer a concentration in human resources.

Is the lack of diversity concentrations and courses in business schools due to the fact that executives don't value diversity enough? That may be a partial explanation. When diversity is little more than sensitivity training or a defense to discrimination lawsuits, diversity is not being fully valued. But the actions and comments of some Fortune 500 companies seem to indicate that diversity is valued.

\subsection{Does business value diversity in higher education?}

Twenty of America's largest and best-known corporations filed a legal brief strongly supporting the University of Michigan in a lawsuit challenging its admissions policies. The brief argued that diversity in higher education plays a critical role in preparing students to be leaders in business and other pursuits that affect the public interest.

The brief stated that racial and ethnic diversity in institutions of higher education is vital to corporations' efforts to hire and maintain an effective workforce. A diverse learning environment in colleges and universities promote the development of a highly skilled, diverse workforce prepared for the opportunities presented by a global economy, said the friends of the court brief.

"Steelcase's success as a global company is dependent on our ability to hire people who have experience in and are knowledgeable about working in a diverse environment with diverse ideas and with people from all walks of life. Without a strong commitment to diversity from the world's leading academic institutions, it will become more and more difficult for multi-national corporations to compete at the global level," said James Hackett, CEO of Steelcase.

But do people develop diversity competencies, as Mr. Hackett suggests, simply by being in a 
diverse environment?

In addition to a strong commitment from academic institutions, the proponents of diversity point to published research that indicates a correlation between a company's commitment to diversity and a positive influence on its bottom line. According to a National Urban League study, companies which employed diversity initiatives generated $18 \%$ greater productivity that the U.S. economy overall (Peoples, 2004).

However, a more detailed look at the research indicates the results are more mixed. A five-year study concluded in 2002 stated that there was no evidence that diversity initiatives produced any business benefits (Bezrukova, Ely, Jackson, Joshi, Jehn, Kochan, Leonard, Levine \& Thomas, 2002). There are some companies who make a commitment to diversity who do not see any positive impact on their bottom line. Other companies do. What is the difference?

According to Dobbin (2007), when a company's managers are culturally aware, able to identify specific problems and remedies, buy-in to the goal of diversity, and feel accountable for the changes necessary to meet diversity goals they are able to increase diversity.

Companies who are adept at implementing diversity initiatives are more competitive for the best talent, more successful in satisfying a diverse customer base, and more adept at producing results from teams populated with a diverse set of employees (Dipboye \& Jayne, 2004). Companies who take an approach to diversity that values all differences (differentiation) and those companies that take a "we are all the same" approach (assimilation) do not see a positive impact to their bottom line. Those companies who combine the two approaches (integration) do see an impact on the bottom line.

Among other things, what this research demonstrates is that leveraging diversity is a skill set and it is a skill set that must be acquired. If it is not acquired through one-day seminars, then how is it acquired? According to Dipboye \& Jayne (2004), companies spend an estimated $\$ 8$ billion dollars on diversity training.

But there is an alternative; if as the amicus brief in the University of Michigan case suggests, the corporate world depends on academic institutions to supply it with qualified people, then business schools are also in a position to provide corporations with the people needed to leverage diversity into a positive impact on the bottom line.

\subsection{Do business schools offer diversity curriculum?}

The problem is few business schools have anything to offer. As recounted above, none of California's business schools accredited by the AACSB offer a diversity concentration. Of the hundreds of classes total taught by those 28 universities only nine of those classes teach 


\section{Macrothink Institute ${ }^{\mathrm{TM}}$}

diversity, none offer more than one diversity course, and none offer a diversity concentration.

And what should those universities offer in relation to diversity? The literature on diversity consistently identifies three areas where leveraging diversity provides value - diversity helps companies compete in the global marketplace for high performing talent; diversity helps a company market and sells to an increasingly diverse customer base, and diversity increases the collective idea generation and problem solving abilities of teams.

A business school concentration in diversity should strive to develop managers who can be successful in those areas.

A 2009 on-line course offered by Cornell University, Diversity and Inclusion for Bottom Line Performance, offers some guidance. The course description begins as follows:

"The management of diversity and inclusion has evolved from handling day-to-day compliance issues to leveraging diversity for competitive advantage. Organizations that no longer see diversity as a legal or moral requirement, but as a competitive advantage, have an opportunity to improve performance at the financial, employee, customer, and community levels.

Diversity and inclusion practices must be embedded in an organizational culture to make a positive impact on performance. This course summarizes the evolution of diversity and inclusion management; outlines key management practices for improving performance, contextualizes diversity in terms of current challenges, and provides direct linkages between diversity and the bottom line at the organizational and functional levels."

\section{Exploration of Multicultural/Diversity Concentration}

In order to meet the needs of companies, as a minimum, a business school diversity concentration should focus on recruitment, sales and marketing, innovation and improved team performance. However, any course or concentration should start with a basic understanding of diversity. As Boyette (2009) said, "diversity does deliver bottom-line benefits for some companies - but only if there's an organizational culture that explicitly acknowledges differences and encourages people to bring all relevant insights and perspectives to their work."

Diversity concentrations could also be added to incorporate the latest trends and challenges faced by businesses. For example, more and more companies are taking serious steps to demonstrate social responsibility. These steps often involve partnerships with community-based organizations. Thus, a class on leveraging community partnerships would provide a benefit.

There is another important benefit of adding a diversity concentration to business schools. 


\section{I Macrothink}

By populating the workplace with managers and executives who possess a strong diversity competency, diversity becomes more organic to organizations. This is important for several reasons - it increases the chances that organizations can leverage diversity into a positive impact on the bottom line, it improves the work environment for all employees, and it reduces corporations' billions spent on diversity training.

Most importantly, when diversity is organic, it increases the chances that diversity becomes engrained in the culture of the organization rather than as a flavor of the month initiative. When diversity becomes part of the way business is done, business is done more effectively. Business schools can make a significant contribution by offering a diversity concentration as an integral part of its curriculum.

\section{References}

Adams, M., \& Zhou-McGovern, Y. (1993, June). Connecting research to college teaching practice: Developmental findings applied to social diversity classes. Paper presented at the 8th Annual Adult Development Society for Research in Adult Development, Amherst, MA.

Bezrukova, B., Ely, R., Jackson, S., Jehn, K., Joshi, A., Leonard, J., Levine, D., Kochan, T., \& Thomas, D. (2002). The Effects of Diversity on Performance: Report of the Diversity Research Network, Human Resource Management Journal. Retrieved February 28, 2009 from http://mitsloan.mit.edu./iwer/pdf/diversity_report.pdf.

Bowman, B. (1994). Cultural Diversity and Academic Achievement. North Central RegionalLaboratory. http://www.ncrel.org/sdrs/areas/issues/educatrs/le0bow.htm.

Boyette, M. (2009). Benefits of diversity in the workplace: What's the bottom line? HR Café. Retrieved February 28, from http://hrcafe.typepad.com/my_weblog/2009/01/benefits-of-diversity-in-the-workplace-whatsthe-bottom-line.html

Bradford, W.D. (2005). Discrimination, Legal Costs and Reputational Costs [Electronic version]. Washington University. Retrieved April 1, 2009 from http://www.fma.org/Chicago/Papers/ Suit090904.pdf

Casey, J. \& Corday, K. (2006). Conversations with the Experts: Business Case for Workforce Diversity. Sloan Work and Family Research Network, Boston College Retrieved February 28, 2009 from http://wfnetwork.bc.edu/The_Network_News/20/The_Network_ News_Interview20.pdf

Clark, C. (2003). Multicultural Education, 10(3), 27-30. Retrieved February 21, 2009, from Multicultural Module database. (Document ID: 320225081). 
Day, N., \& Glick, B. (2000). Teaching diversity: A study of organizational needs and diversity curriculum in higher education. Journal of Management Education. Thousand Oaks: June 2000. Vol. 24, Iss. 3; pg. 338, 15 pages.

Dobbin, F., Kalev, A. \& Kelly, E. (2007). Diversity Management in Corporate America [Electronic version]. Contexts

Dipboye, R.L., \& Jayne, M.E.A. (2004). Leveraging Diversity to Improve Business Performance: Research Findings and Recommendations for Organizations. Human Resource Management, Winter 2004, Vol. 43, No. 4, Pp. 409-424. Retrieved February 28, 2009 from http://www.utm.edu/staff/mikem/documents/Diversity.pdf

Ely, R.J. \& Thomas, D.A. (2002). Making Differences Matter: A New Paradigm for Managing Diversity [Electronic version]. HBR On Point.

Gallos, J. V., \& Ramsey, V. J. (1997). Teaching diversity: Listening to the soul, speaking from the heart. San Francisco: Jossey-Bass.

Garcia, R. (1998). Teaching for Diversity. Bloomington: Phi Delta Kappa Educational Foundation.

Gundling, E. and Zanchettin, A. (2006). Global Diversity: How to Win Winning Customers and Engaging Employees within World Markets. Boston: Brealey, Nicholas Publishing.

Hernandez-Sheets, R. (2003). Historical analysis of the reluctance to school children of color: Requiring an English, white, and middle-class uniform. Multicultural Education, 10(3), 62-63. Retrieved February 21, 2009, from Multicultural Module database. (Document ID: 320225471).

Hubbard, D.E. (2007). The Business Case for Diversity. The Multicultural Advantage.

$\begin{array}{llll}\text { Retrieved } \quad \text { February 28, from } & 2009 \text { r }\end{array}$ http://www.multiculturaladvantage.com/business-case-for-diversity- recruiting.asp

Hutchens, J. (2007). Employee Diversity Training Doesn't Work. Time, Retrieved April 1, 2009 from http://www.time.com/time/magazine/article/0,9171,1615183,00.html

Jost, M, Whitfield, E. \& Jost, M. (2005). When the rules are fair, but the game isn't. Multicultural Education, 13(1), 14-21. Retrieved February 21, 2009, from Multicultural Module database. (Document ID: 898561911).

Lagace, M. (2004). Racial Diversity Pays Off. HBS Working Knowledge. Retrieved February 28, 2009 from http://hbswk.hbs.edu/archive/4207.html 


\section{I Macrothink}

Lauber, M. (1998). Studies Show That Diversity in Workplace is Profitable. Villagelife. Retrieved February 28, 2009 from http://www.villagelife.org/news/archives/diversity.html

Lee, G. (2002). Realities and challenges facing multicultural education. Multicultural Education, 9(4), 36-37. Retrieved February 21, 2009, from Multicultural Module database. (Document ID: 126920521).

Locatelli, P. (2002, May). Education for globalization. America, 186(17), 8-11. Retrieved February 21, 2009, from Research Library Core database. (Document ID: 120983853).

Lynch, James (1989). Multicultural Education: A Global Approach. Bristol: Falmer Press.

Matuk, L., \& Ruggirello, T. (2007). Culture Connection Project: Promoting Multiculturalism in Elementary Schools. Canadian Journal of Public Health, 98(1), 26-9. Retrieved February 21, 2009, from Health Module database. (Document ID: 1207782161$)$.

Miller, A, Smith, V.E., \& Underwood, A. (1996) Managing Diversity It's Not Just A Matter Of 'Sensitivity Training.' The Boss Has To Become A Believer--And Say So, Newsweek. Retrieved April 1, 2009 from http://www.newsweek.com/id/103449/output/print

No Author. (2009) Cornell University. 2009 eCornell Catalog. Retrieved from http://web.search.cornell.edu/search?output=xml_no_dtd\&client=default_frontend\&proxystyl esheet=default_frontend $\& q=$ diversity $\% 20$ courses

No Author. (2007) Healthy California. California Department of Public Health. Retrieved from http://ww2.cdph.ca.gov/data/indicators/goals/Documents/discussion.pdf

No author (2000). Fortune 500 Corporations File Brief in Support of Diversity in Higher Education, Jenner \& Block press release, Retrieved February 28, 2009 from http://www.umich.edu/ bhlumrec/a/admissions/releases/fortune.html

Peoples, J.C. (2004). Diversity practices that work: The American worker speaks. (Electronic version). National Urban League

Roberson, Q.M. (2009). Diversity and Inclusion for Bottom-line Performance. eCornell. $\begin{array}{lllll}\text { Retrieved } & \text { February } & 2809 & \text { from }\end{array}$ http://www.ecornell.com/individual-course-list/?crs=ILRHR553

Rodriguez, F. (1983). Education in a Multicultural Society. New York: University of America Press.

Smith, J. H. (2008, August). Reflections on equity, diversity, and schooling, 


\section{Macrothink}

45(12), 2208-2209. Retrieved May 24, 2009, from Research Library Core database. (Document ID: 1608632481).

Thomas, D. A. \& Ely, R.1. (1996). Making differences matter: A new paradigm for managing diversity. Harvard Business Review, 74(5), 79-90.

Trompenaars, Fons \& Turner, Charles H. (1997). Riding the Waves of Culture. New York: McGraw-Hill.

Walker, P. (2006). Business schools expand global reach. CNN. Retrieved February 28, 2009 from http://www.cnn.com/2006/BUSINESS/12/25/execed.global3/index.html

unknown. "Definition of Diversity." Iowa State University's college of liberal arts and science. LAS. http://www.las.iastate.edu/diversity/definition.shtml.

About the Authors

Roxanne Helm-Stevens joined Azusa Pacific University in 2000 as a professor in the School of Business and Management. She serves on the Teaching Best Practices and Assessment committee. In 2005, Helm-Stevens was invited to chair the Master in Human Resources and Organizational Development program. And, most recently, she has played a significant role for the school by taking the lead on several curriculum development projects.

Linda Hunt is a 2009 graduate of Azusa Pacific University having served in an executive leadership position in the corporate sector in management, finance and as the CFO of a foundation. Currently she is working in the non-profit sector. Linda has a passion for communicating global diversity and faith integration issues and is known for building community, business and educational partnerships. She graduated Cum Laude from Milliken University in Decatur, Illinois and recently completed her master's degree at Azusa Pacific University in Azusa in Human Resource and Organizational Development. 